\title{
Differential accumulation of energy by the colour morphs of the pea aphid Acyrthosiphon pisum (Hemiptera: Aphididae) mirrors their ecological adaptations
}

\author{
Seyed Mohammad AHSAEI, Seyed Mohammad TABADKANI*, Vahid HOSSEININAVEH*, Hossein ALLAHYARI \\ and MAHDIEH BIGHAM
}

Department of Plant Protection, College of Agriculture and Natural Resources, University of Tehran, PO Box 4111, Karaj, Iran

Key words. Hemiptera, Aphididae, Acyrthosiphon pisum, adaptation, colour morph, dispersal, available energy, environmental factors, pea aphid, polymorphism, reproduction, specialization

\begin{abstract}
The pea aphid, Acyrthosiphon pisum (Hemiptera: Aphididae), is a well-studied species in terms of its colour polymorphism, where it occurs as two distinct colour morphs, red and green. It is proposed that the occurrence and maintenance of this polymorphism is an adaptive response to environmental factors, in particular natural enemies and host plant quality. We hypothesized that these adaptations are directly mirrored in the energy reserves accumulated by the different colour morphs during their pre-adult stages and reflect their specialization for particular ecological roles. We quantitatively measured the different energy reserves of red and green pea aphids and found that the total energy reserves of these morphs did not differ. Interestingly, these reserves were made up of different components in the red and green colour morphs. There was a higher percentage content of water-soluble carbohydrates and lipids in the red clones and higher percentage content of protein in green clones. These finding are in accordance with green clones being more fecund than red ones and needing more protein for reproduction than red clones, which produce more winged offspring when crowded or in response to the presence of natural enemies and so, need more lipids and carbohydrates to fuel their walking and flight. Apparently, different colour morphs are physiologically specialized to adjust their energy reserves in relation to their specific ecological adaptations and maximize their fitness in terms of dispersal, reproduction, defense and surviv al.
\end{abstract}

\section{INTRODUCTION}

Phenotypic polymorphism (i.e. differences in body characters, such as colour and size of individuals of the same species) is widespread in animal taxa (Maynard Smith, 1998). Many species of aphids (Hemiptera: Aphididae) are characterized by the production of a range of colour morphs that may differ in some biological properties such as growth rate, host range and susceptibility to natural enemies (Markkula, 1963; Losey et al., 1997; Braendle \& Weisser, 2001). Several hypotheses have been proposed to justify the occurrence and maintenance of polymorphism in natural populations of aphids (reviewed by Futuyma, 1986). According to most of these hypotheses, differential pressures of environmental conditions, especially natural enemies, on different colour morphs maintain colour polymorphism in aphid populations (Agawa \& Kawata, 1995; Losey et al., 1997).

The pea aphid Acyrthosiphon pisum (Harris) is an important agricultural pest of a wide range of leguminous crops, causing direct damage through phloem feeding and indirect economic loss because it is a vector of economically important plant viruses (Dixon, 1985; Lane \& Walters, 1991). Pea aphids occur in two colour morphs, red and green (Weisser \& Braendle, 2001). Laboratory crosses between red and green morphs suggest that body colour determination in pea aphids is genetically based, with the morphs remaining distinct throughout the vegeta- tive season because the aphids reproduce parthenogenetically (Losey et al., 1997; Caillaud \& Losey, 2010). However, some environmental factors (such as symbiotic microorganisms) are also thought to affect aphid body colour (Tsuchida et al., 2010).

During a long evolutionary history, ecological and behavioural specializations have been evolved by each colour morph to maximize their inclusive fitness in terms of reproduction, dispersal, defense and survival. For example, red clones of the pea aphid drop off host plants more frequently than green ones when artificially disturbed (Braendle \& Weisser, 2001; Farhoudi, 2012). Interestingly, red clones are more susceptible to general predators such as ladybirds and dropping off host plants enables them to escape from predators (Losey et al., 1997; Farhoudi, 2012). On the other hand, green clones are more frequently parasitized by parasitic wasps (Losey et al., 1997) and so, rely more on chemical defense than dropping off host plants (Farhoudi, 2012). More interestingly, green clones of pea aphids are believed to be better adapted to cold conditions, i.e., they occur earlier in the vegetative season, than red ones (Valmalette et al., 2012) probably due to the lower abundance of parasitoids in comparison to predators at that time of the year. On the other hand, red clones are more abundant than green ones during the warmer months (especially summer), probably due to their greater dispersal ability in terms of producing a higher proportion of winged offspring when crowded

\footnotetext{
* Corresponding authors; e-mails: tabadkani@ut.ac.ir (S.M. Tabadkani), vnaveh@ut.ac.ir (V. Hosseininaveh).
} 
(Weisser \& Braendle, 2001), more efficient defense against natural enemies (Braendle \& Weisser, 2001) etc. Although, there are many other examples of ecological and behavioural differences between these two colour morphs, there is no experimental study on whether environmental conditions differentially affect the physiology of red and green clones. In this study, we quantitatively measured the energy reserves (including water-soluble carbohydrates, lipids, proteins and glycogen) of red and green pea aphids in order to determine if there is any difference between the physiological statuses of these two colour morphs. We used a recently developed biochemical method (Foray et al., 2012) by which, both total and individual energy reserves can be quanti ed at the individual level and used as a reliable indicator to evaluate the allocation of energy by insects to their diverse biological activities.

\section{MATERIAL AND METHODS}

\section{Plants and insects}

Broad bean plants, Vicia fabae (Fabaceae), were used as the host plant for the pea aphids. Seeds of broad beans were planted in plastic pots $(20 \mathrm{~cm}$ heigh and $20 \mathrm{~cm}$ in diameter) containing sawdust. Red and green pea aphids were separately collected from alfalfa fields in the Hashtgerd region (Karaj, Iran) and transferred to the host plants. The aphids were transferred to new plants every five days to prevent the production of winged aphids. The stock colony of pea aphids was reared in a greenhouse at $22 \pm 3{ }^{\circ} \mathrm{C}, 65 \%$ relative humidity and a photoperiod of $16 \mathrm{~L}: 8 \mathrm{D}$. At the time of the study, the aphids had been reared under these controlled conditions for at least 50 generations.

\section{Sample preparation}

The last nymphal instars of the red and green morphs, selected from the same host plants, were separately homogenized for $30 \mathrm{~s}$ in $180 \mu \mathrm{L}$ of aqueous lysis buffer solution $\left(100 \mathrm{mM} \mathrm{KH}_{2} \mathrm{PO}_{4}, 1 \mathrm{mM}\right.$ dithiothreitol and $1 \mathrm{mM}$ ethylenediaminetetraacetic acid, $\mathrm{pH}$ 7.4) using a plastic micropestle. There were three replicates of each of the determinations in the following assays.

\section{Quantification of the energy reserves}

The measurements of energy reserves in the whole body of red and green morphs were determined mainly following the method used by Foray et al. (2012) with slight modifications. Protein concentrations in homogenates of the whole body of red and green colour morphs of the pea aphid were measured according to Lowry et al. (1951). Bovine serum albumin at appropriate concentrations was used as the standard. Total carbohydrates were dissolved by addition of $20 \mu \mathrm{L}$ of sodium sulfate solution (20\%) to 180 homogenate (van Handel, 1965; van Handel \& Day, 1988). Total lipid and water-soluble carbohydrates were solubilized by mixing the solution with $1500 \mu \mathrm{L}$ of a chloroform-methanol solution $(1: 2 \mathrm{v} / \mathrm{v}$ ) (van Handel, 1965; van Handel \& Day, 1988). Each sample was then centrifuged at $16,000 \mathrm{rpm}$ for $15 \mathrm{~min}$ at $4^{\circ} \mathrm{C}$. The supernatant was transferred to a new microtube for water-soluble carbohydrate determination. The pellet was used for the determination of the glycogen content. Glycogen and water-soluble carbohydrate contents were determined using the colorimetric method, using anthrone reagent and D-glucose as the standard (van Handel, 1965).

Vanillin reagent and cholesterol (as the standard) were used for measuring total lipid content (van Handel, 1985b). One hun-

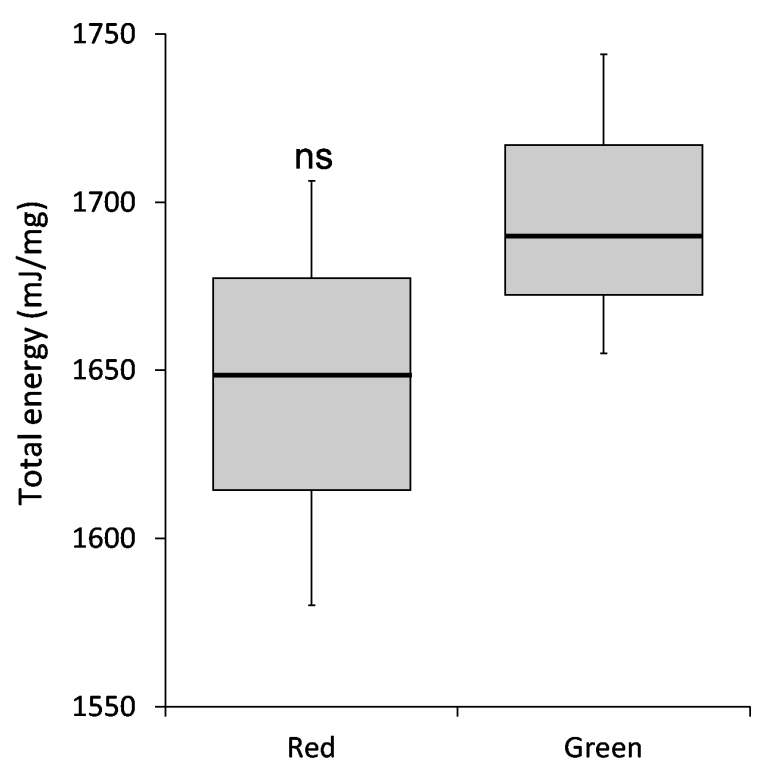

Fig. 1. Average total energy content $\left(\mathrm{mJ} \mathrm{mg}^{-1}\right)$ of the carbohydrate, glycogen, lipid and protein reserves of red and green pea aphids; ns - non-significant.

dred $\mu \mathrm{L}$ of the supernatant from centrifuged chloroformmethanol solution was transferred into new microtubes and heated until complete solvent evaporation. Ten microlitres of $98 \%$ sulphuric acid was added to each microtube, which was then incubated at $90^{\circ} \mathrm{C}$ for $2 \mathrm{~min}$. Vanillin reagent $(190 \mu \mathrm{L})$ was added to each ice pre-cooled microtube. The absorbance was determined at $540 \mathrm{~nm}$ after $15 \mathrm{~min}$ incubation at room temperature.

The different energy reserves (lipids, proteins, carbohydrates, and glycogen) were converted into energetic equivalents. The energy equivalents of these reserves are $39,500 \mathrm{~mJ} \mathrm{mg}^{-1}$ for lipids, $24,000 \mathrm{~mJ} \mathrm{mg}^{-1}$ for proteins and $17,500 \mathrm{~mJ} \mathrm{mg}^{-1}$ for carbohydrates (Gnaiger, 1983).

\section{Data analysis}

Data were analyzed using SPSS computer software, Version 15 (SPSS Inc., Chicago, IL). Independent $t$-tests were used to compare the average energy contents of green and red pea aphids.

\section{RESULTS}

Our results revealed that the average total energy reserves (i.e. sum of the energy in the carbohydrate, glycogen, protein and lipid reserves) of green and red pea aphids did not differ significantly ( $\mathrm{t}$-test: $\mathrm{t}=1.14, \mathrm{P}>$ 0.05) (Fig. 1). Carbohydrate, glycogen, lipid and protein contents of both red and green pea aphids were also individually compared. We found that the most important energy reserve in red morphs were lipids $(53.20 \%$ of total energy reserves) followed by soluble carbohydrates $(24.28 \%)$ and proteins $(22.06 \%)$. In green aphids, however, proteins were the most abundant energy reserve (42.14\%) followed by lipids (41.06\%) and soluble carbohydrates (16.04\%) (Fig. 2). We detected a very low content of glycogen in both red and green colour morphs (only $0.45 \%$ and $0.75 \%$ of total energy reserves in red and green aphids, respectively) (Figs 1 and $3 \mathrm{~d}$ ). 


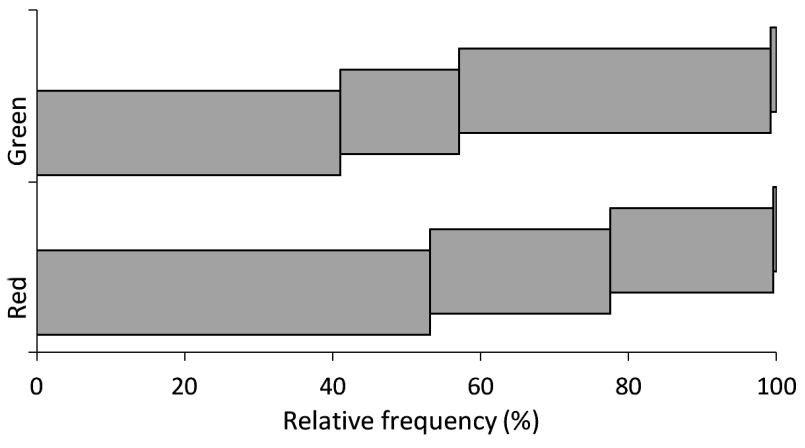

Fig. 2. Percentage of the reserves in the form of lipids, soluble carbohydrates, proteins and glycogen (from left to right, respectively) in red and green pea aphids.

The lipid and soluble carbohydrate reserves in red pea aphids were significantly higher than in green ones (t-test, $\mathrm{t}=5.14(\mathrm{P}<0.01)$ and $\mathrm{t}=3.66(\mathrm{P}<0.05)$ for lipids and soluble carbohydrates, respectively) (Fig. 3a, b). However, the average protein reserves were significantly greater in the green colour morph ( $\mathrm{t}$-test, $\mathrm{t}=4.94, \mathrm{P}<$ 0.01) (Fig. 3c). There was no significant difference in the glycogen content of the two colour morphs ( $\mathrm{t}$-test, $\mathrm{t}=$ 2.179, P > 0.05) (Fig. 3d).

\section{DISCUSSION}

Our results revealed that there were significantly higher contents of proteins, but lower contents of lipids and soluble carbohydrates in green than in red aphids (Fig. 2). Interestingly, the total available energy calculated as the sum of the energy content of lipids, carbohydrates, proteins, and glycogen did not differ statistically between these two morphs (Fig. 1). This means that each colour morph contains the same amount of energy but in different substrates. The most abundant reserves in red aphids were lipids and soluble carbohydrates, which implies that they are quantitatively the most important energy sources in this colour morph. In green clones, however, proteins were the most abundant followed by lipids and soluble carbohydrates (see Fig. 2).

Carbohydrates and lipids are the most important storage fuels of insects and are utilized more frequently than other reserves to obtain energy for muscular activity (Martin \& Lieb, 1979; Rankin \& Burchsted, 1992; Chapman, 1998). The use of carbohydrates and lipids as energy sources for locomotion and flight is well documented for different insect orders, including Hymenoptera, Diptera, Orthoptera, Lepidoptera, Hemiptera etc. (Hansford \& Johnson, 1975; Martin \& Lieb, 1979). These are also the most important resources used, separately or intermittently, as energy sources during starvation (Newton, 1954; Lim \& Lee, 1981; Wheeler \& Buck, 1992; Perez-Mendoza et al., 1999; Olson et al., 2000; Satake et al., 2000; Rivero \& West, 2002). It is advantageous for insects to store energy in the form of lipids because they provide almost two times more metabolic water and almost eight times more energy per unit weight than carbohydrates (Downer \& Mathews, 1976; Chapman, 1998; Perez-Mendoza et al., 1999). It is generally accepted that lipids accumulated during pre-adult stages are the major energy reserve for non-feeding or starved insects (Urs \& Hopkins, 1973; Lim \& Lee, 1981). Additionally, it is suggested that the main destination of extra sucrose in aphids are lipids (Febvay et al., 1999). We found a significantly higher content of lipids and soluble carbohydrates in red than green pea aphids. These differences are associated with differences in the ecological and behavioural characteristics of these colour morphs. Red pea aphids are more active than the green ones in terms of dispersal both by walking and flying [Weisser \& Braendle, 2001; Braendle

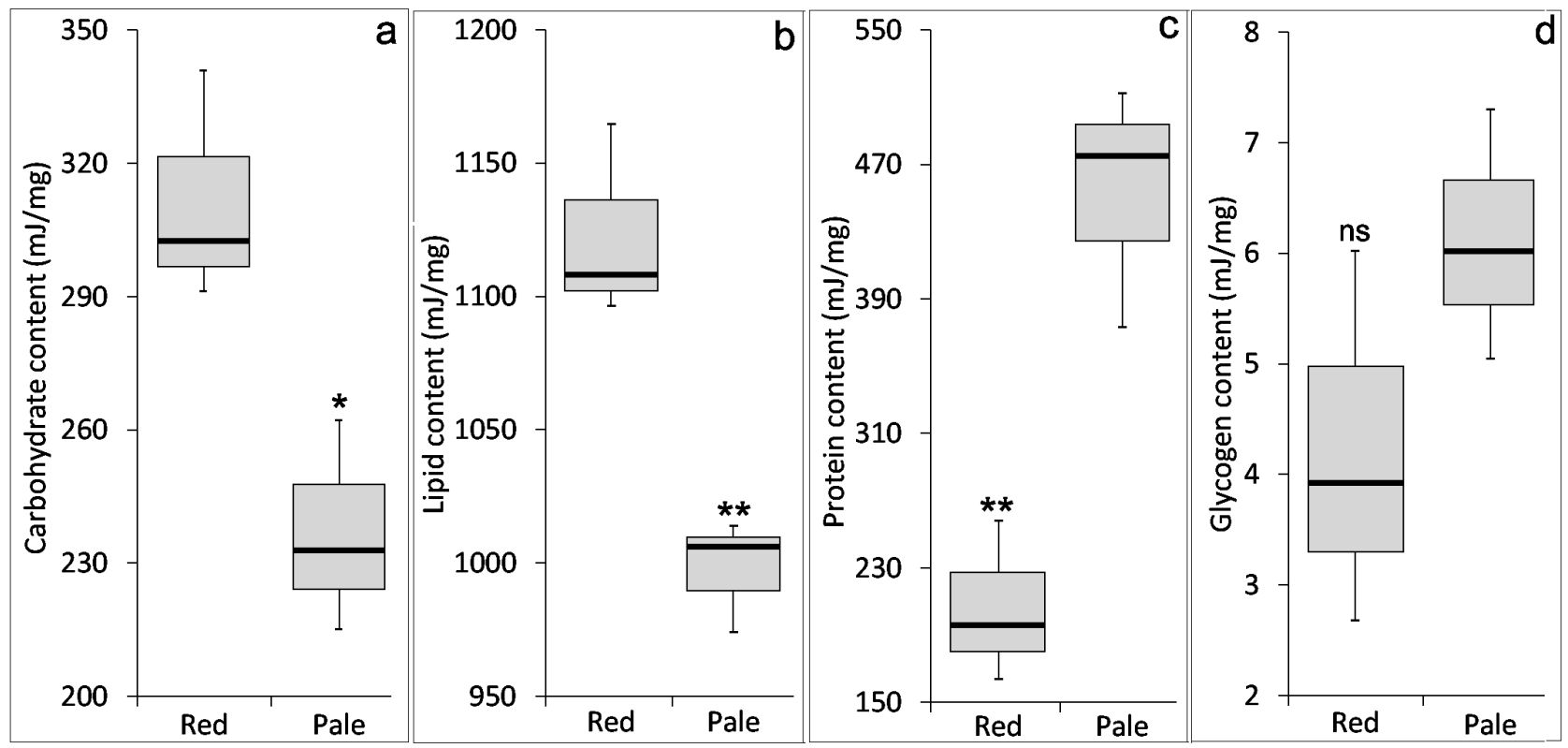

Fig. 3. Average energy equivalents $\left(\mathrm{mJ} \mathrm{mg}^{-1}\right)$ of the carbohydrates (a), lipids (b), proteins (c), and glycogen (d) in red and green pea aphids; ns- non-significant; * - significant at $0.05 ; * *$ - significant at 0.01 . 
\& Weisser, 2001; Farhoudi, 2012 (our own population)]. They produce a higher proportion of winged offspring in response to crowding or attack by predators (Weisser \& Braendle, 2001; Farhoudi, 2012) and drop from host plants more frequently when artificially disturbed than green aphids (Braendle \& Weisser, 2001; Farhoudi, 2012). These observations indicate that red aphids are generally more active than green aphids, which is associated with their storing more lipids and carbohydrates during their pre-adult stages. Interestingly, winged individuals have a lower reproductive potential than apterous individuals (Raikhel \& Dhadialla, 1992). So, it is not surprising that red aphids have a lower fecundity than green aphids (Markkula, 1963). The protein content of insects, on the other hand, is not seen as a source of energy but of protein for development, maintenance, morphogenesis and reproduction (Brown, 1980; Slanski \& Scriber, 1985; Karowe \& Martin, 1989; Raikhel \& Dhadialla, 1992). Proteins may even be of more importance for aphids as there are three generations present within one viviparous female (inside the mature embryos in the abdomen of each aphid there are the first embryos of the third generation) (Stevens, 1904). Green clones of pea aphids produce more offspring than red ones (Markkula, 1963). This may account for the higher accumulation of proteins in green pea aphids.

This study highlights a new physiological aspect of colour polymorphism in aphids. Aphid polymorphism is a response to a complex set of environmental pressures, in particular the different adaptations of each color morph for avoiding natural enemies (Losey et al., 1997) and responding to changes in host plant quality (Braendle \& Weisser, 2001; Weisser \& Braendle, 2001). These differences are reflected in the energy reserves of each colour morph, which are associated with their specific ecological role in natural populations. This specialization enables aphids to respond appropriately to changes in their environment and so maximize their inclusive fitness in terms of dispersal, reproduction, defense and survival. Future studies of the energy reserves and energy allocation of different clones (races) of the pea aphid that feed on different host plants may reveal some interesting aspects of these specializations, a phenomenon that is thought to underlie host-dependent genetic divergence and speciation (see Peccoud et al., 2009a, b). Additionally, an awareness of the accumulation pattern of energy in winged aphids may result in a more comprehensive understanding of their specialization in relation to their role in the population.

ACKNOWLEDGEMENTS. The authors would like to acknowledge the great help they received from F. Farhoudi and F. Khojasteh in discussion and analyzing data. This work was funded by the University of Tehran. The authors have no conflict of interest.

\section{REFERENCES}

Agawa H. \& Kawata M. 1995: The effect of color polymorphism on mortality in the aphid Macrosiphoniella yomogicola. - Ecol. Res. 10: 301-306.
BraendeE C. \& Weisser W.W. 2001: Variation in escape behavior of red and green clones of the pea aphid. - J. Insect Behav. 14: 497-509.

BROWN J.J. 1980: Haemolymph protein reserves of diapausing and nondiapausing codling moth larvae, Cydia pomonella (L.) (Lepidoptera: Tortricidae). - J. Insect Physiol. 26: 487-491.

CAIllaud M.C. \& Losey J.E. 2010: Genetics of color polymorphism in the pea aphid, Acyrthosiphon pisum. - J. Insect Sci. 10: 95.

Chapman R.F. 1998: The Insects: Function and Structure. Cambridge University Press, Camridge, 788 pp.

Dixon A.F.G. 1985: Aphid Ecology. Chapman and Hall, London, $300 \mathrm{pp}$.

Downer R.G.H. \& Matthews J.R. 1976: Patterns of lipid distribution and utilization in insects. - Am. Zool. 16: 733-745.

FARHoudi F. 2012: A Comparison on the Developmentalreproductive Parameters of Red and Green Morphs of Pea Aphid Acyrthosiphon pisum (Harris) (Hemiptera: Aphididae) and its Defensive Behavior Against the Ladybird, Hippodamia variegata. MSc thesis, University of Tehran, 73 pp. [in Persian with English abstr.].

Febvay G., Rahbe Y., Rynkiewicz M., Guillaud J. \& Bonnot G. 1999: Fate of dietary sucrose and neosynthesis of amino acids in the pea aphid, Acyrthosiphon pisum, reared on different diets. - J. Exp. Biol. 202: 2639-2652.

Foray V., Pelisson P.F., Bel-Venner M.C., Desouhant E., Venner S., Menu F., Giron D. \& Rey B. 2012: A handbook for uncovering the complete energetic budget in insects: the van Handel's method (1985) revisited. - Physiol. Entomol. 37: 295-302.

Futuyma D.J. 1986: Evolutionary Biology. 2nd ed. Sinauer Associates, Sunderland, MA, xiv $+600 \mathrm{pp}$.

HANSFORD R.G. \& JoHnson R.H. 1975: The nature and control of tricarboxylate cycle in beetle flight muscle. - Biochem. J. 148: $389-402$.

GNAiger E. 1983: Calculation of energetic and biochemical equivalents of respiratory oxygen consumption. In Gnaiger E. \& Forstner H. (eds): Polarographic Oxygen Sensors. Aquatic and Physiological Applications. Springer, Berlin, pp. 337-345.

Karowe D.N. \& Martin M.M. 1989: The effects of quantity and quality of nitrogen diet on the growth, efficiency of food utilization, nitrogen budget, and metabolic rate of fifth-instar Spodoptera eridania larvae (Lepidoptera: Noctuidae). - J. Insect Physiol. 35: 699-708.

LANe A. \& Walters K.F.A. 1991: Effect of pea aphid (Acyrthosiphon pisum) on the yield of combining peas. - Aspest Appl. Biol. 27: 363-368.

Lim S.J \& LeE S.S. 1981: The effects of starvation on haemolymph metabolites, fat body, and ovarian development in Oxya japonica (Acrididae: Orthoptera). - J. Insect Physiol. 27: 93-96.

Losey J.E., Ives A.R., Harmon J., Brown C. \& Ballantyne F. 1997: A polymorphism maintained by opposite patterns of parasitism and predation. - Nature 388: 269-272.

LOUGHEED K. 2012: Photosynthesis-like process found in insects. - Nature (DOI: 10.1038/nature.2012.11214).

Lowry O.H., Rosembrough N.J., Farr A.L. \& RandDall R.J. 1951: Protein measurement with the Folin phenol reagent. J. Biol. Chem. 193: 267-275.

MarkKula M. 1963: Studies on the pea aphid, Acyrthosiphon pisum, with special reference to the differences in the biology of the green and red forms. - Ann. Agr. Fenn. 2: 1-30.

Martin M.M. \& Lieb T.J. 1979: Patterns of fuel utilization by the thoracic muscles of adult worker ants. The use of lipid by a hymenopteran. - Comp. Biochem. Physiol. 64: 387-390. 
Maynard Smith J. 1998: Evolutionary Genetics. 2nd ed. Oxford University Press, Oxford, $354 \mathrm{pp}$.

Newton C.J. 1954: Effects of starvation on composition of Japanese beetle larvae (Popillia japonica Newman). - Am. Nat. 85: $337-352$.

Olson D.M., Fadamiro H., Lundgren J.G. \& Heimpel G.E. 2000: Effects of sugar feeding on carbohydrate and lipid metabolism in a parasitoid wasp. - Physiol. Entomol. 25: $17-26$.

Peccoud J., Ollivier A., Plantegenest M. \& Simon J.C. 2009a: A continuum of genetic divergence from sympatric host races to species in the pea aphid complex. - Proc. Natl. Acad. Sci. USA 106: 7495-7500.

Peccoud J., Simon J.C., McLaughlin H.J. \& Moran N.A. 2009b: Post-Pleistocene radiation of the pea aphid complex revealed by rapidly evolving endosymbionts. - Proc. Natl. Acad. Sci. USA 106: 16315-16320.

Perez-Mendoza J., Dover B.A., Hagstrum D.W. \& Hopkins T.L. 1999: Effect of crowding, food deprivation, and diet on flight initiation and lipid reserves of the lesser grain borer, Rhyzopertha dominica. - Entomol. Exp. Appl. 91: 317-326.

RAIKHEL A.S. \& Dhadialla T.S. 1992: Accumulation of yolk proteins in insect oocytes. - Annu. Rev. Entomol. 37: $217-251$.

RANKIN M.A. \& Burchsted J.C.A. 1992: Cost of migration in insects. - Annu. Rev. Entomol. 37: 533-559.

Rivero A. \& West S.A. 2002: The physiological costs of being small in a parasitic wasp. - Evol. Ecol. Res. 4: 407-420.

Satake S., Kawabe Y. \& Mizoguchi A. 2000: Carbohydrate metabolism during starvation in the silkworm Bombyx mori. - Arch. Insect Biochem. Physiol. 44: 90-98.

SLANSKI F. JR \& SCRIBER M.R. 1985: Food consumption and utilization. In Kerkut S.A. \& Gilbert J.F. (eds): Comprehen- sive Insect Physiology, Biochemistry and Pharmacology. Pergamon Press, Oxford, pp. 87-151.

Stevens N.M. 1904: A study of the germ cells of Aphis rosae and Aphis oenotherae. - J. Exp. Zool. 2: 313-333.

Tsuchida T., Koga R., Horikawa M., Tsunoda T., Maoka T., Matsumoto S., Simon J.C. \& Fukatsu T. 2010: Symbiotic bacterium modifies aphid body color. - Science 330: 1102-1104.

URS K.D.C. \& HopKINS T.L. 1973: Effect of moisture on the lipid content and composition of two strains of Tenebrio molitor L. (Coleoptera: Tenebrionidae). - J. Stored Prod. Res. 8: 299-305.

Valmalette J.C., Dombrovsky A., Brat P., Mertz C., CapoVILLA M. \& RoBichon A. 2012: Light-induced electron transfer and ATP synthesis in a carotene synthesizing insect. - Sci. Rep. 2: 579.

vAN HANDEl E. 1965: Microseparation of glycogen, sugars, and lipids. - Anal. Biochem. 11: 266-271.

VAN HANDEL E. 1985a: Rapid determination of glycogen and sugars in mosquitoes. - J. Am. Mosq. Control Assoc. 1: 299-301.

VAN HANDEL E. 1985b: Rapid determination of total lipids in mosquitoes. - J. Am. Mosq. Control Assoc. 1: 302-304.

van Handel E. \& Day J. 1988: Assay of lipids, glycogen and sugars in individual mosquitoes: correlations with wing length in fieldcollected Aedes vexans. - J. Am. Mosq. Control Assoc. 4: 549-550.

WeIsSer W.W. \& Braendle C. 2001: Body color and genetic variation in winged morph production in the pea aphid. Entomol. Exp. Appl. 99: 217-223.

WheELer D.E. \& Buck N.A. 1992: Protein, lipid and carbohydrate utilization during metamorphosis in the western fire ant, Solenopsis xyloni. - Physiol. Entomol. 17: 397-403.

Received October 26, 2012; revised and accepted December 11, 2012 